Special Issue on

"Building Local Capacity for Long-term Disaster Resilience"

Part 2

\title{
Toward an Enhanced Concept of Disaster Resilience: A Commentary on Behalf of the Editorial Committee
}

By William Siembieda

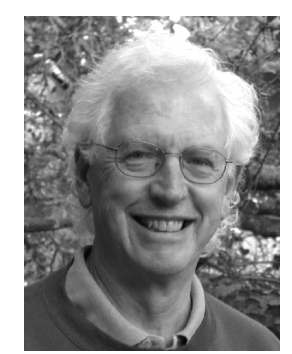

Kenneth C. Topping, FAICP

Member, JDR Board

Special Issue Editor

Topping Associates International, USA

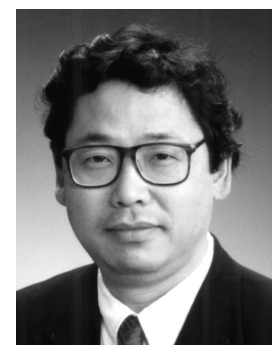

Haruo Hayashi, Ph.D.

Member, JDR Board Special Issue Co-Editor Kyoto University, Japan

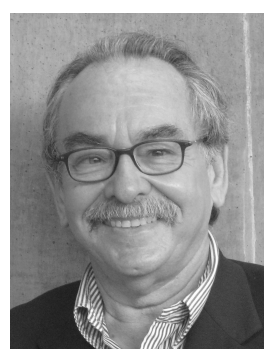

William Siembieda, Ph.D. Special Issue Co-Editor California Polytechnic State University, USA

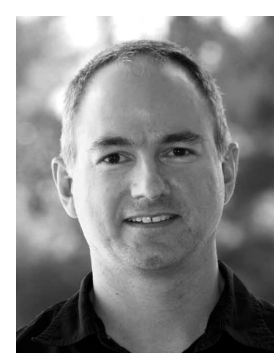

Michael Boswell, Ph.D.

Special Issue Co-Editor California Polytechnic State University, USA

\section{Introduction}

This Special Issue (Part 2) expands upon the theme "Building Local Capacity for Long-term Disaster Resilience" presented in Special Issue Part 1 (JDR Volume 5, Number 2, April 2010) by examining the evolving concept of disaster resilience and providing additional reflections upon various aspects of its meaning. Part 1 provided a mixed set of examples of resiliency efforts, ranging from administrative challenges of integrating resilience into recovery to the analysis of hazard mitigation plans directed toward guiding local capability for developing re- 
siliency. Resilience was broadly defined in the opening editorial of Special Issue Part 1 as "the capacity of a community to: 1) survive a major disaster, 2) retain essential structure and functions, and 3) adapt to post-disaster opportunities for transforming community structure and functions to meet new challenges."

In this editorial essay we first explore in Section 2 the history of resilience and then locate it within current academic and policy debates. Section 3 presents summaries of the papers in this issue.

\section{Why is Resilience a Contemporary Theme?}

There is growing scholarly and policy interest in disaster resilience. In recent years, engineers [1], sociologists [2], geographers [3], economists [4], public policy analysts [5, 6], urban planners [7], hazards researchers [8], governments [9], and international organizations [10] have all contributed to the literature about this concept. Some authors view resilience as a mechanism for mitigating disaster impacts, with framework objectives such as resistance, absorption, and restoration [5]. Others, who focus on resiliency indicators, see it as an early warning system to assess community resiliency status $[3,8]$. Recently, it has emerged as a component of social risk management that seeks to minimize social welfare loss from catastrophic disasters [6].

Manyena [11] traces scholarly exploration of resilience as an operational concept back at least five decades. Interest in resilience began in the 1940s with studies of children and trauma in the family and in the 1970s in the ecology literature as a useful framework to examine and measure the impact of assault or trauma on a defined eco-system component [12]. This led to modeling resilience measures for a variety of components within a defined ecosystem, leading to the realization that the systems approach to resiliency is attractive as a cross-disciplinary construct. The ecosystem analogy however, has limits when applied to disaster studies in that, historically, all catastrophic events have changed the place in which they occurred and a "return to normalcy" does not occur. This is true for modern urban societies as well as traditional agrarian societies.

The adoption of "The Hyogo Framework for Action 2005-2015" (also known as The Hyogo Declaration) provides a global linkage and follows the United Nations 1990s International Decade for Natural Disaster Reduction effort. The 2005 Hyogo Declaration's definition of resilience is: "The capacity of a system, community or society potentially exposed to hazards to adapt by resisting or changing in order to reach and maintain an acceptable level of functioning and structure." The proposed measurement of resilience in the Hyogo Declaration is determined by "the degree to which the social system is capable of organizing itself to increase this capacity for learning from past disasters for better future protection and to improve risk reduction measures." While very broad, this definition contains two key concepts: 1) adaptation, and 2) maintaining acceptable levels of functioning and structure. While adaptation requires certain capacities, maintaining acceptable levels of functioning and structure requires resources, forethought, and normative 
action. Some of these attributes are now reflected in the 2010 National Disaster Recovery Framework published by the U.S. Federal Emergency Management Agency (FEMA) [13].

With the emergence of this new thinking on resilience related to disasters, it is now a good time to reflect on the concept and assess what has recently been said in the literature. Bruneau et al. [1] offer an engineering sciences definition for community seismic resilience: "The ability of social units (e.g., organizations, communities) to mitigate hazards, contain the effects of disasters when they occur, and carry out recovery activities in ways that minimize social disruption and mitigate the effects of future earthquakes." Rose [4] writes that resiliency is the ability of a system to recover from a severe shock. He distinguishes two types of resilience: (1) inherent - ability under normal circumstances and (2) adaptive - ability in crisis situations due to ingenuity or extra effort. By opening up resilience to categorization he provides a pathway to establish multi-disciplinary approaches, something that is presently lacking in practice. Rose is most concerned with business disruption which can take extensive periods of time to correct. In order to make resource decisions that lower overall societal costs (economic, social, governmental and physical), Rose calls for the establishment of measurements that function as resource decision allocation guides. This has been done in part through risk transfer tools such as private insurance. However, it has not been well-adopted by governments in deciding how to allocate mitigation resources.

We need to ask why the interest in resilience has grown? Manyena [11] argues that the concept of resilience has gained currency without obtaining clarity of understanding, definition, substance, philosophical dimensions, or applicability to disaster management and sustainable development theory and practice. It is evident that the "emergency management model" does not itself provide sufficient guidance for policymakers since it is too command-and-control-oriented and does not adequately address mitigation and recovery. Also, large disasters are increasingly viewed as major disruptions of the economic and social conditions of a country, state/province, or city. Lowering post-disaster costs (human life, property loss, economic advancement and government disruption) is being taken more seriously by government and civil society. The lessening of costs is not something the traditional "preparedness" stage of emergency management has concerned itself with; this is an existing void in meeting the expanding interests of government and civil society.

The concept of resilience helps further clarify the relationship between risk and vulnerability. If risk is defined as "the probability of an event or condition occurring [14]" then it can be reduced through physical, social, governmental, or economic means, thereby reducing the likelihood of damage and loss. Nothing can be done to stop an earthquake, volcanic eruption, cyclone, hurricane, or other natural event, but the probability of damage and loss from natural and technological hazards can be addressed through structural and non-structural strategies. Vulnerability is the absence of capacity to resist or absorb a disaster impact. Changes in vulnerability can then be achieved by changes in these capacities. In this regard, 
Franco and Siembieda describe in this issue how coastal cities in Chile had low resilience and high vulnerability to the tsunami generated by the February 2010 earthquake, whereas modern buildings had high resilience and, therefore, were much less vulnerable to the powerful earthquake. We also see how the framework for policy development can change through differing perspectives. Eisner discusses in this issue how local non-governmental social service agencies are building their resilience capabilities to serve target populations after a disaster occurs, becoming self-renewing social organizations and demonstrating what Leonard and Howett [6] term "social resilience." All of the contributions to this issue illustrate the lowering of disaster impacts and strengthening of capacity (at the household, community or governmental level) for what Alesch [15] terms "postevent viability" - a term reflecting how well a person, business, community, or government functions after a disaster in addition to what they might do prior to a disaster to lessen its impact. Viability might become the definition of recovery if it can be measured or agreed upon.

\section{Contents of This Issue}

The insights provided by the papers in this issue contribute greater clarity to an understanding of resilience, together with its applicability to disaster management. In these papers we find tools and methods, process strategies, and planning approaches. There are five papers focused on local experiences, three on state (prefecture) experiences, and two on national experiences.

The papers in this issue reinforce the concept of resilience as a process, not a product, because it is the sum of many actions. The resiliency outcome is the result of multiple inputs from the level of the individual and, at times, continuing up to the national or international organizational level. Through this exploration we see that the "resiliency" concept accepts that people will come into conflict with natural or anthropogenic hazards. The policy question then becomes how to lower the impact(s) of the conflict through "hard or soft" measures (see the Special Issue Part 1 editorial for a discussion of "hard" vs. "soft" resilience).

\section{Local level}

Go Urakawa and Haruo Hayashi illustrate how post-disaster operations for public utilities can be problematic because many practitioners have no direct experience in such operations, noting that the formats and methods normally used in recovery depend on personal skills and effort. They describe how these problems are addressed by creating manuals on measures for effectively implementing postdisaster operations. They develop a method to extract priority operations using business impact analysis (BIA) and project management based business flow diagrams (BFD). Their article effectively illustrates the practical aspects of strengthening the resiliency of public organizations.

Richard Eisner presents the framework used to initiate the development and implementation of a process to create disaster resilience in faith-based and community- 
based organizations that provide services to vulnerable populations in San Francisco, California. A major project outcome is the Disaster Resilience Standard for Community- and Faith-Based Service Providers. This "standard" has general applicability for use by social service agencies in the public and non-profit sectors.

Alejandro Linayo addresses the growing issue of technological risk in cities. He argues for the need to understand an inherent conflict between how we occupy urban space and the technological risks created by hazardous chemicals, radiation, oil and gas, and other hazardous materials storage and movement. The paper points out that information and procedural gaps exist in terms of citizen knowledge (the right to know) and local administrative knowledge (missing expertise). Advances and experience accumulated by the Venezuela Disaster Risk Management Research Center in identifying and integrating technological risk treatment for the city of Merida, Venezuela, are highlighted as a way to move forward.

L. Teresa Guevara-Perez presents the case that certain urban zoning requirements in contemporary cities encourage and, in some cases, enforce the use of building configurations that have been long recognized by earthquake engineering as seismically vulnerable. Using Western Europe and the Modernist architectural movement, she develops the historical case for understanding discrepancies between urban zoning regulations and seismic codes that have led to vulnerable modern building configurations, and traces the international dissemination of architectural and urban planning concepts that have generated vulnerability in contemporary cities around the world.

Jung Eun Kang, Walter Gillis Peacock, and Rahmawati Husein discuss an assessment protocol for Hazard Mitigation Plans applied to 12 coastal hazard zone plans in the state of Texas in the U.S. The components of these plans are systematically examined in order to highlight their respective strengths and weaknesses. The authors describe an assessment tool, the plan quality score (PQS), composed of seven primary components (vision statement, planning process, fact basis, goals and objectives, inter-organizational coordination, policies \& actions, and implementation), as well as a component quality score (CQS).

\section{State (Prefecture) level}

Charles Real presents the Natural Hazard Zonation Policies for Land Use Planning and Development in California in the U.S. California has established statelevel policies that utilize knowledge of where natural hazards are more likely to occur to enhance the effectiveness of land use planning as a tool for risk mitigation. Experience in California demonstrates that a combination of education, outreach, and mutually supporting policies that are linked to state-designated natural hazard zones can form an effective framework for enhancing the role of land use planning in reducing future losses from natural disasters.

Norio Maki, Keiko Tamura, and Haruo Hayashi present a method for local government stakeholders involved in pre-disaster plan making to describe performance measures through the formulation of desired outcomes. Through a case study approach, Nara and Kyoto Prefectures' separate experiences demonstrate how to conduct Strategic Earthquake Disaster Reduction Plans and Action Plans 
that have deep stakeholder buy-in and outcome measurability. Nara's plan was prepared from 2,015 stakeholder ideas and Kyoto's plan was prepared from 1,613 stakeholder ideas. Having a quantitative target for individual objectives ensures the measurability of plan progress. Both jurisdictions have undertaken evaluations of plan outcomes.

Sandy Meyer, Eugene Henry, Roy E. Wright and Cynthia A. Palmer present the State of Florida in the U.S. and its experience with pre-disaster planning for postdisaster redevelopment. Drawing upon the lessons learned from the impacts of the 2004 and 2005 hurricane seasons, local governments and state leaders in Florida sought to find a way to encourage behavior that would create greater community resiliency in 2006. The paper presents initial efforts to develop a post-disaster redevelopment plan (PDRP), including the experience of a pilot county.

\section{National level}

Bo-Yao Lee provides a national perspective: New Zealand's approach to emergency management, where all hazard risks are addressed through devolved accountability. This contemporary approach advocates collaboration and coordination, aiming to address all hazard risks through the " $4 \mathrm{Rs"} \mathrm{-} \mathrm{reduction,} \mathrm{readiness,}$ response, and recovery. Lee presents the impact of the Resource Management Act (1991), the Civil Defence Emergency Management Act (2002), and the Building Act (2004) that comprise the key legislation influencing and promoting integrated management for environment and hazard risk management.

Guillermo Franco and William Siembieda provide a field assessment of the February 27, 2010, M8.8 earthquake and tsunami event in Chile. The papers present an initial damage and life-loss review and assessment of seismic building resiliency and the country's rapid updating of building codes that have undergone continuous improvement over the past 60 years. The country's land use planning system and its emergency management system are also described. The role of insurance coverage reveals problems in seismic coverage for homeowners. The unique role of the Catholic Church in providing temporary shelter and the central government's five-point housing recovery plan are presented. A weakness in the government's emergency management system's early tsunami response system is noted.

\section{Acknowledgements}

The Editorial Committee extends its sincere appreciation to both the contributors and the JDR staff for their patience and determination in making Part 2 of this special issue possible. Thanks also to the reviewers for their insightful analytic comments and suggestions.

Finally, the Committee wishes to again thank Bayete Henderson for his keen and thorough editorial assistance and copy editing support. 


\section{References:}

[1] M. Bruneau, S. E. Chang, R. T. Eguchi, G. C. Lee, T. D. O'Rourke, A. M. Reinhorn, M. Shinozuka, K. Tierney, W. A. Wallace, and D. von Winterfeldt, "A Framework to Quantitatively Assess and Enhance the Seismic Resilience of Communities," Earthquake Spectra, Vol.19, No.4, pp. 733-752, November 2003.

[2] K. Tierney, "Societal Dimensions of Earthquakes and Other Disasters: Findings in Search of Theory," Proceedings of the 9th US National and 10th Canadian Conference on Earthquake Engineering, July 25-29, 2010, Toronto, Ontario, Canada: Paper \#1898, 2010.

[3] S. L. Cutter, C. G. Burton, and C. T. Emrich, "Disaster Resilience Indicators for Benchmarking Baseline Conditions." Journal of Homeland Security and Emergency Management, Vol.7, Iss.1, Article 51, 2010.

[4] A. Rose, "Defining and Measuring Economic Resilience to Disasters," Disaster Prevention and Management, Vol.13, No.4, pp. 307-314, 2004.

[5] H. Kahan, A. C. Allen, and J. K. George, "An Operational Framework for Resilience," Journal of Homeland Security and Emergency Management, Vol.6, Iss.1, Article 53, 2009.

[6] H. B. Leonard and A. R. Howitt, "Advance Recovery and the Development of Resilient Organizations and Societies," In Integrative Risk Management: Advanced Disaster Recovery, by Simon Woodward (Editor), pp. 45-58, Zurich: Swiss Reinsurance Company Ltd., 2010.

[7] S. E. Chang, "Urban Disaster Recovery: A Measurement Framework and Its Application to the 1995 Kobe Earthquake," In Disasters, Vol.34, No.2, pp. 303-327, October 26, 2009.

[8] W. G. Peacock, H. Kunreuther, W. H. Hooke, S. L. Cutter, S. E. Chang, and P. R. Berke, "Toward a Resiliency and Vulnerability Observatory Network: RAVON," HRRC reports: 08-02R, 2008.

[9] U.S. Department of Homeland Security, Risk Steering Committee; DHS Risk Lexicon, Washington, D.C.: 2008.

[10] UNISDR (United Nations International Strategy for Disaster Risk Reduction), "Hyogo Framework for 2005-2015: Building the Resilience of Nations and Communities to Disasters," 2005.

[11] S. B. Manyena, "The Concept of Resilience Revisited," In Disasters, 30(4): 433-50, 2006.

[12] C. S. Holling, "Resilience and stability of ecological systems," Annual Review of Ecological Systems 4:1-23, 1973.

[13] Federal Emergency Management Agency (FEMA), "National Disaster Recovery Framework," February 5, 2010. http://www.fema.gov/recoveryframework/ [accessed May 15, 2010].

[14] D. S. Miletti, "Disasters by Design,” Washington, D.C.: Joseph Henry Press, 1999.

[15] D. J. Alesch, "Complex Urban Systems and Extreme Events: Toward a Theory of Disaster Recovery," Arlington, VA.: Public Entity Risk Institute, 2005. 